\title{
A IMPORTÂNCIA DO SPRING COMO UMA FERRAMENTA DE ANÁLISE AMBIENTAL: CASO DA BACIA HIDROGRÁFICA DO UERÊ/MS
}

\author{
Paulo Henrique Vieira ${ }^{1}$
}

Adalto Moreira Braz ${ }^{2}$

Patrícia Helena Mirandola ${ }^{3}$

\begin{abstract}
Resumo: O presente trabalho tem como enfoque demonstrar a importância do SIG (Sistema de Informação Geográfica), no caso desse trabalho o SPRING, como uma ferramenta que auxilie o usuário deste programa nas análises ambientais necessárias para o seu estudo. O Objetivo deste trabalho foi usar esses sistemas como uma poderosa aliada do pesquisador na análise ambiental, neste caso específico da bacia hidrográfica do Uerê, localizada no município de Bataguassu que fica na micro região de nova Andradina, situada no estado do Mato Grosso do Sul. Para isso foi necessário seguir alguns procedimento metodológicos: Trabalhos de Gabinete se resume a revisão bibliográfica que abrangem o tema estudado; Composição da Estrutura Sistêmica, o sistema estudado integra um componente maior e assim sucessivamente; Levantamento de Dados consiste em um levantamento de dados utilizados no trabalho entre eles, aquisição de dados orbitais, imagens SRTM entre outros; Técnicas de Geoprocessamento, divididas entre três etapas Pré-geoprocessamento, Geoprocessamento e Pós-geoprocessamento; Criação de um Banco de Dados, com informações referentes ao objeto estudado; e Divulgação dos Resultados. As bacias hidrográficas são importantes objetos de análise, principalmente aos geógrafos que tem a facilidade de integra dados sociais e ambientais que integram esse complexo sistema ambiental que são as bacias hidrográficas
\end{abstract}

Palavras-chave: SIG, Análise Ambiental, Bacia Hidrográfica.

1Pós Graduando no curso de geografia pela UFMS. paulohenrique.vieira@yahoo.com.br ${ }^{2}$ Graduando do curso de geografia pela UFMS.adaltobraz.geografia@gmail.com ${ }^{3}$ Prof $^{a}{ }^{-a}{ }^{a}$ do curso de geografia pela UFMS. patríciaufmsgeografia@gmail.com 


\section{Introdução}

Atualmente, as bacias hidrográficas vêm tendo estudos corriqueiramente, devido a sua importância e por se tratar de um espaço complexo onde ocorrem as interações entre as atividades antrópicas e meio ambiente, pesquisadores de diversas áreas vem estudando as bacias hidrográficas, entre elas a Geografia que vem dando contribuições significativas acerca do tema.

Bacia Hidrográfica pode ser considerada como a área de drenagem que contém o conjunto de cursos d'água que convergem para esse rio, até a seção considerada, sendo, portanto, limitada em superfície a montante, pelos divisores de água, que correspondem aos pontos mais elevados do terreno e que separam bacias adjacentes. O conjunto de cursos d'água, denominada rede de drenagem, está estruturado, com todos os seus canais, para conduzir a água e os detritos que lhe são fornecidos pelos terrenos da bacia de drenagem.

A quantidade de água que atinge os rios está na dependência das características físicas de sua bacia hidrográfica, da precipitação total e de seu regime, bem como das perdas devidas à evapotranspiração total e á infiltração. As características físicas são definidas pelas características morfológicas, representadas pelo tipo de relevo, forma, orientação e declividade da bacia de drenagem e pelos aspectos geológicos, representados pelas estruturas, tipos litológicos, mantos de intemperismo e solos. Além destes aspectos, a cobertura vegetal e o tipo de ocupação da bacia exercem também uma influência importante nas relações entre infiltração e escoamento superficial em uma bacia de drenagem.

As bacias hidrográficas vêm sendo modificadas pelas atividades antrópicas com o decorrer do tempo. O homem transforma o espaço da melhor forma que lhe convém, de acordo com suas necessidades. O homem transforma o espaço através de derrubada de matas, da implantação de pastagens e cultivos, da construção de estradas, portos e aeroportos, represas, retificação e canalização de cursos d'água, da implantação de indústrias e áreas urbanas (FLORENZANO, 2002). Os cenários ambientais construídos ou transformados pelo homem ocupam a maior parte dos sistemas ambientais. 


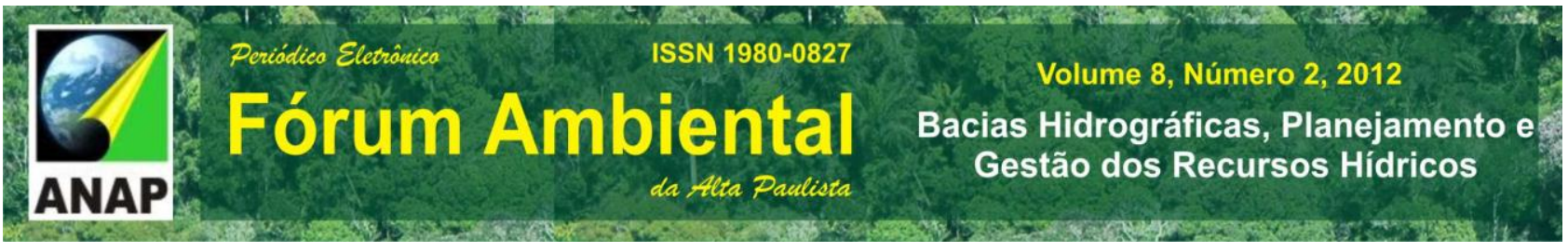

Para analisar essas modificações no meio ambiente nada melhor do que uma ferramenta que auxilie o pesquisador na tomada de decisões, ou seja, um Sistema de Informações Geográficas, SIG. O SIG deve ser compreendido como uma vigorosa ferramenta para apoiar a tomada de decisão por parte do usuário. A sua estrutura deve, nesse sentido, ser muito bem planejada para que a interação homem-máquina se dê de maneira eficiente e atenda às necessidades dos usuários (FITZ, 2008).

Para evitar isso às geotecnologias presente no Sensoriamento Remoto podem ser uma ótima ferramenta, para a gestão dos recursos naturais, através de imagens de satélites, fotografias aéreas, entre outros itens. Embora relativamente recente, o uso de imagens de satélite tem crescido a cada ano. Os sistemas para manuseá-las tem tornado as imagens de satélites ferramentas úteis, cada vez mais disponíveis a todos os tipos de usuários [...] (PARANHOS FILHO, 2008). As geotecnologias fazem com que se minimize os custos econômicos e se otimizem os resultados.

Nesse quesito de analisar as modificações ambientais ocorridas, a melhor forma de se chegar a resultados satisfatórios, são as análises multitemporais de uso e ocupação da terra. O que é feito com rapidez e agilidade com o SIG, no caso deste trabalho o SPRING ${ }^{\circledR}$ 5.0.6. distribuído gratuitamente pelo INPE ( Instituto Nacional de Pesquisas Espaciais), o SPRING e seus componentes (Scarta e Impima principalmente), demonstraram resultados satisfatório nas análises ambientais e multitemporais feitas sobre a bacia hidrográfica do Uerê, mostradas mais a frente.

Uma das vantagens de se usar o software SPRING, é criação de um banco de dados, onde todas as informações geradas são armazenadas de uma forma segura e onde os dados ficam de fácil manipulação.

As tecnologias presente no Sensoriamento Remoto (entre elas os SIGs) tem facilidade em representar o espaço geográfico em representações cartográficas (mapas), por análises ambientais com a utilização desses programas estão se expandindo fazendo com que essa ferramenta se cada vez mais utilizada nos estudos de diversas áreas.

O objetivo deste trabalho é demonstrar a importância do SPRING, nas análises ambientais, demonstrando isso em mapas de uso e ocupação da terra (através de imagens orbitais do LANDSAT 5), da bacia hidrográfica do Uerê, além de análises dessas modificações. 


\subsection{Importância das imagens Landsat 5}

O uso de dados orbitais é essencial através deles observam-se as diferentes feições do território estudado, e com esse dado se faz os mapas através do SIG. Nas Imagens de satélites são identificadas as feições sobre a superfície terrestre, considerando que cada um dos componentes naturais contidos nelas, possui um comportamento espectral específicos nos diferentes comprimentos de ondas. As técnicas de processamento digital de imagens permitem que as imagens sejam classificadas através do processo de extração de informação para reconhecer padrões e objetos homogêneos (BANDEIRA; ALVES e MELO, 2010)

Através desse processo se faz os mapas temáticos identificando cada classe de cobertura da terra existente no objeto de estudo.

Essas atividades só são possíveis graças as imagens do Landsat 5, satélite americano lançado em 1986 e ate o fim de 2011, continuava registrando imagens do globo terrestre.

No presente trabalho utilizou as imagens Landsat 5, dos anos de 2006 e 2011, ambas referentes ao mês de junho, o objeto de estudo possui Órbita e Ponto de 225 e 75 respectivamente, cada imagem Landsat possui uma órbita e ponto diferente, seria como uma identidade de cada imagem.

\subsection{Localização da área de estudo}




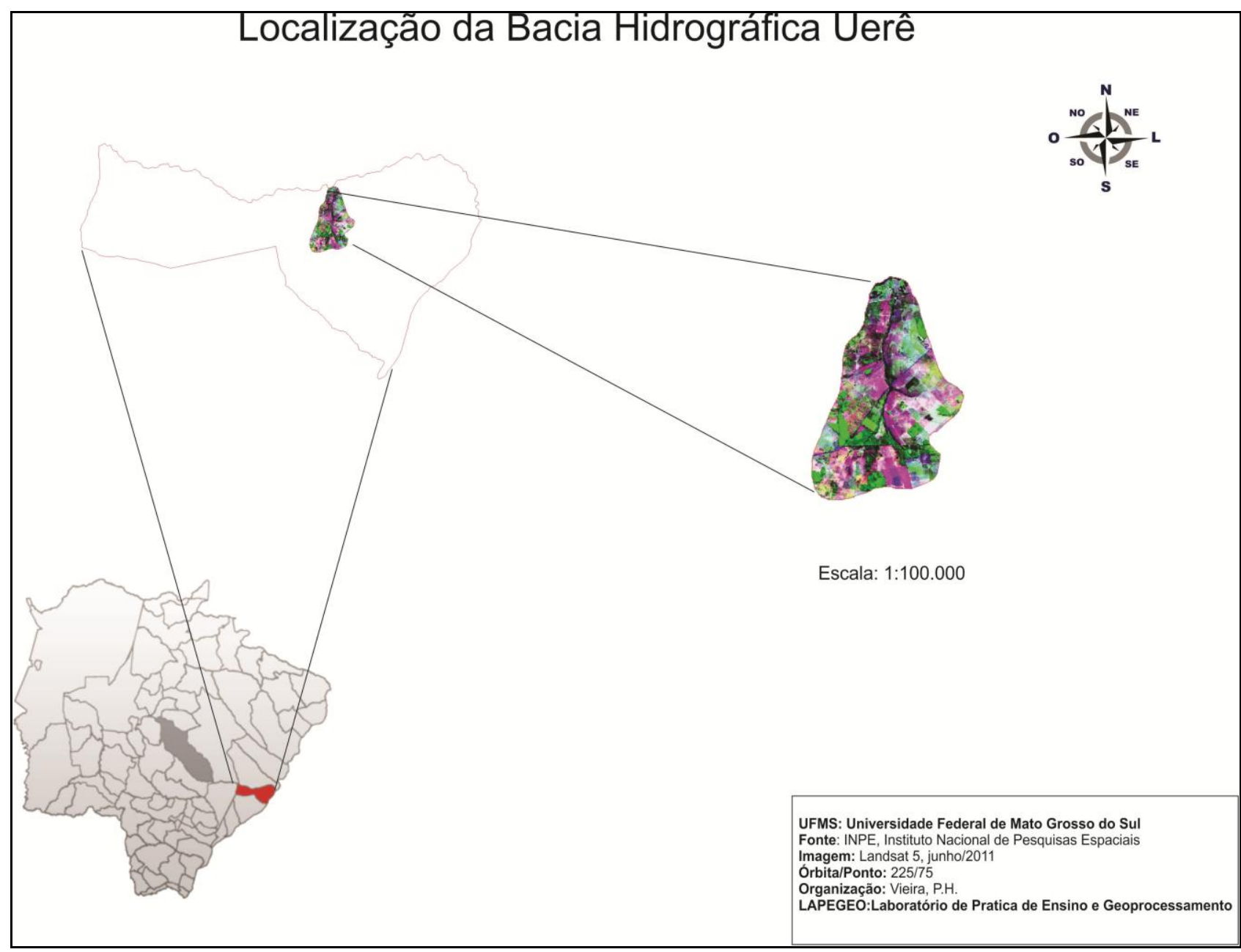

Figura 1 - Mapa de Localização da área de estudo

O objeto de estudo é a bacia hidrográfica do Uerê, localizado no município de Bataguassu/MS, este último localiza-se na costa leste do estado. Bataguassu é conhecida como a cidade Portal do MS, e faz divisa com o estado de São Paulo, cidade de Presidente Epitácio. O município fica a uma distância de $335 \mathrm{Km}$ de Campo Grande, capital do estado de Mato Grosso do Sul.

A bacia hidrográfica fina na parte norte do estado próximo ao sítio urbano do município de Bataguassu.

\section{Metodologia}


Os procedimentos metodológicos baseiam-se nos seguintes autores: Xavier-daSilva e Goés; Gilberto Câmara; Bertalanff. E a metodologia do trabalho foi dividida em etapas, como as mostradas a seguir:

Etapa 1 - Trabalhos de gabinete: essa etapa consiste em resumo bibliográfico acerca da proposta de trabalho.

Etapa 2 - Composição da estrutura sistêmica: Parte do pressuposto que a bacia hidrográfica faz parte de um componente maior, Bataguassu, que esse também integra um sistema maior e assim sucessivamente. E para entender os problemas do local é preciso entender os sistemas como um todo.

Etapa 3 - Levantamento de dados: se resume na aquisição de dados, entre eles imagens de satélite, imagens SRTM, utilizadas para a delimitação do objeto de estudo entre outros dados.

Etapa 4 - Técnicas de Geoprocessamento: esta etapa divide-se em três procedimentos que são Pré-Geoprocessamento, organização dos dados adquiridos; Geoprocessamento, tratamento e análise dos dados orbitais, inclusive a produção dos mapas e Pós-Geoprocessamento, consiste na confecção final dos mapas, inclusão de rosa dos ventos, escala e legenda.

Etapa 5 - Criação de um Banco de Dados: a Criação de um Banco de Dados Digitais (BDG) é feito pelo programa SPRING, antigamente as informações era encontradas em papel de fácil manuseio, mas de dificuldade de manutenção, atualmente com o computador essas informações ficam armazenadas de uma forma segura, e esse BDG, armazena dados referentes ao objeto estudado, no caso deste trabalho a bacia hidrográfica.

Etapa 6 - Divulgação dos Resultados: Após a organização dos dados no BDG, a próxima etapa é a exposição destes dados. 


\section{Resultados}

Passado alguns anos do início do projeto Spring ${ }^{\circledR}$ muito se evoluiu, novos softwares do programa foram elaborados (no presente trabalho utiliza-se o modelo 5.0.6), com melhorias na sua utilização, facilitando assim a conclusão de trabalhos.

A facilitação do processo de aquisição de imagens de satélite, disponível gratuitamente no site do INPE como imagens do CBERS e LANDSAT, deram um impulso para que as geotecnologias se expandissem, permitindo assim um maior número de usuário dessas ferramentas, fazendo com que tivesse inúmeros trabalhos utilizando as técnicas de Sensoriamento Remoto.

O enfoque principal deste trabalho tem de fazer é mostrar a capacidade do SIG em gerar mapas que possam facilitar o zoneamento territorial e ambiental, para que propostas de planejamento sejam alcançadas com agilidade.

No artigo foram gerados mapas temáticos da bacia hidrográfica foram produzidos com o auxilio do SPRING e serão mostrados a seguir: 
Mapa de uso e ocupação da terra da bacia hidrografia Uerê/Ms

\section{LEGENDA}

Pastagem

Vegetação campestre

Vegetação natural

Vegetação úmida

Drenagem
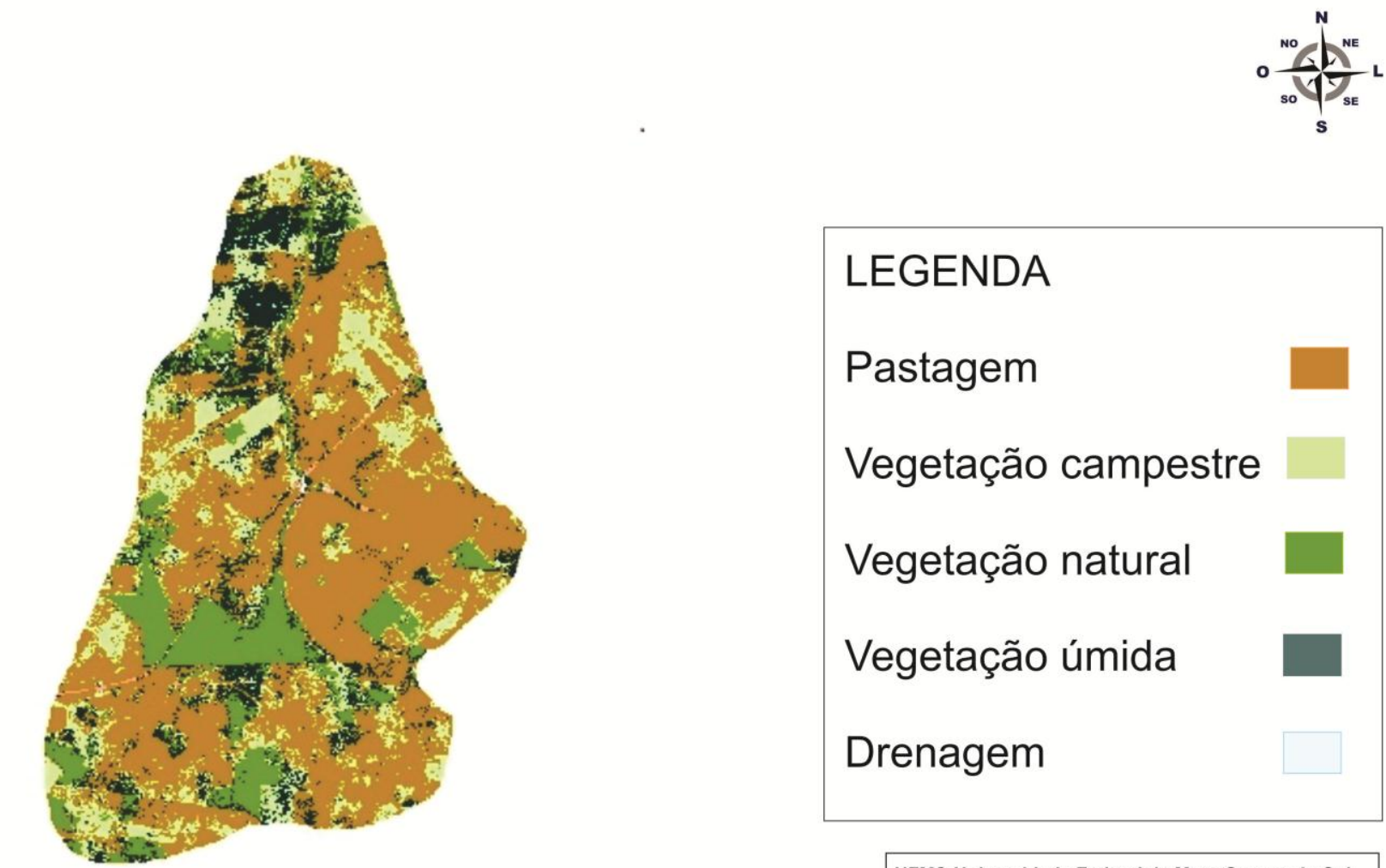

Escala:1:100.000

UFMS:Universidade Federal de Mato Grosso do Sul Imagem: Landsat 5, junho/2006

Órbita/Ponto:225/75

Organização: Vieira P.H.

LAPEGEO:Laboratório de Prática de Ensino e Geografia

Figura 2 - Mapa de uso e ocupação da terra de 2006

É possível notar a predominância da área de pastagem em toda a bacia hidrográfica, por todo o percurso do córrego encontramos vegetação úmida, o que representa a mata auxiliar, sendo que próximo a nascente encontramos grande quantidade de vegetação natural ou área florestal, garantindo assim a preservação da nascente. A vegetação campestre no Mato Grosso do Sul como um todo é utilizado para o uso intensivo do gado (PARANHOS FILHO, 2008).

As cores utilizadas para representar as classes de cobertura da terra nos mapas são aquelas definidas no manual técnico do IBGE (2006)

A respectiva bacia é um afluente do rio Pardo, grande rio que separa Bataguassu do município de Santa Rita do Pardo, esse rio faz parte da bacia hidrográfica do rio Paraná, que por sinal banha o município de Bataguassu. 
Mapa de uso e ocupação da terra da bacia hidrografia Uerê/Ms

Escala:1:100.000

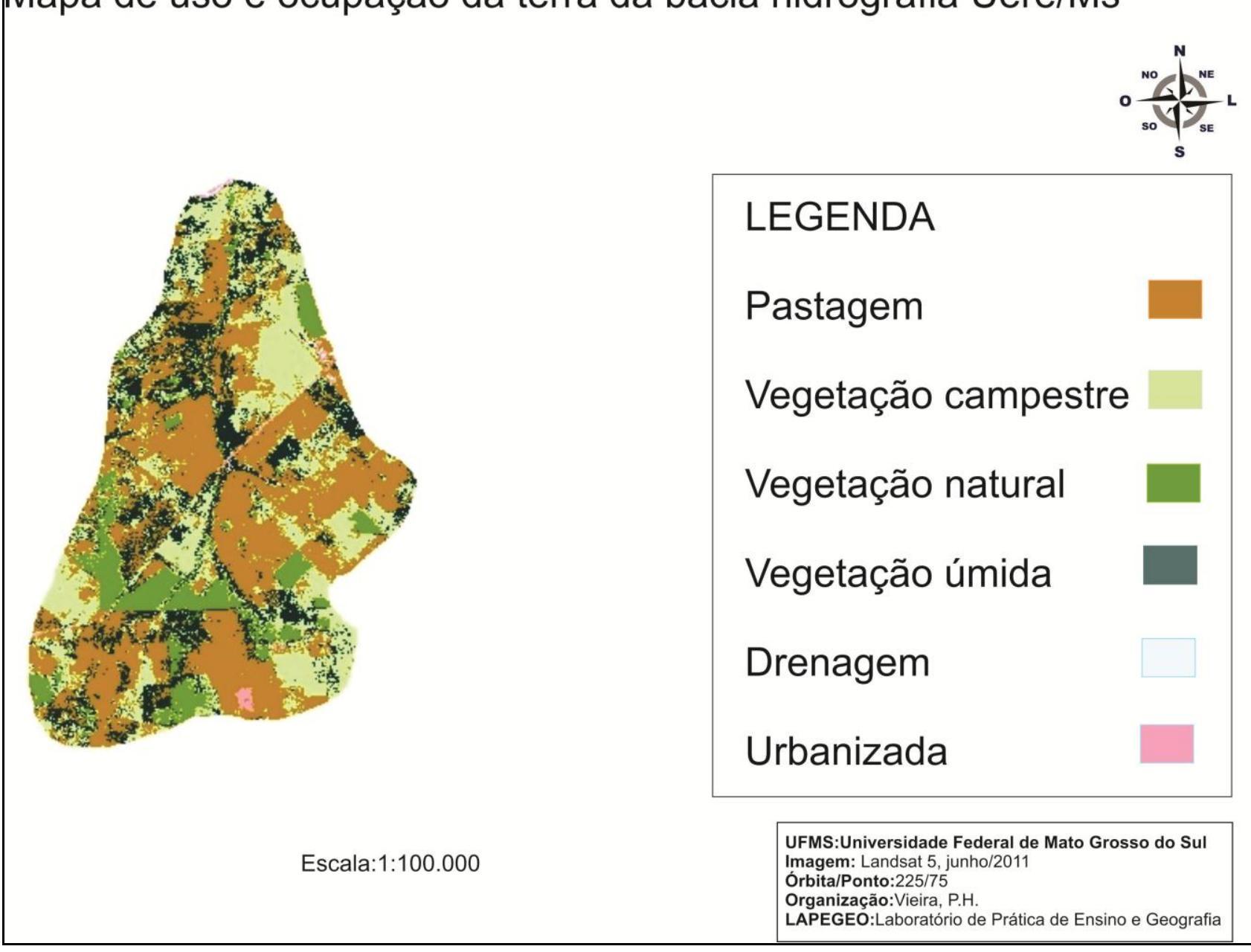

Figura 3 - Mapa de uso e ocupação da terra de 2011

No mapa de 2011, ainda fica claro a predominância da pastagem presente na área de estudo, houve uma pequena redução na área de vegetação natural, a parte mais concentrada de vegetação natural ainda é na nascente do córrego. A vegetação úmida ainda encontra-se próximo a todo o percurso do córrego, houve um grande aumento na área de vegetação campestre, consequentemente aumento da presença de gado, podendo causar a degradação do gado através do pisoteio, causando assoreamento do córrego e erosão.

Encontra-se próximo a nascente área urbanizada, podendo ser sede de alguma fazenda. 


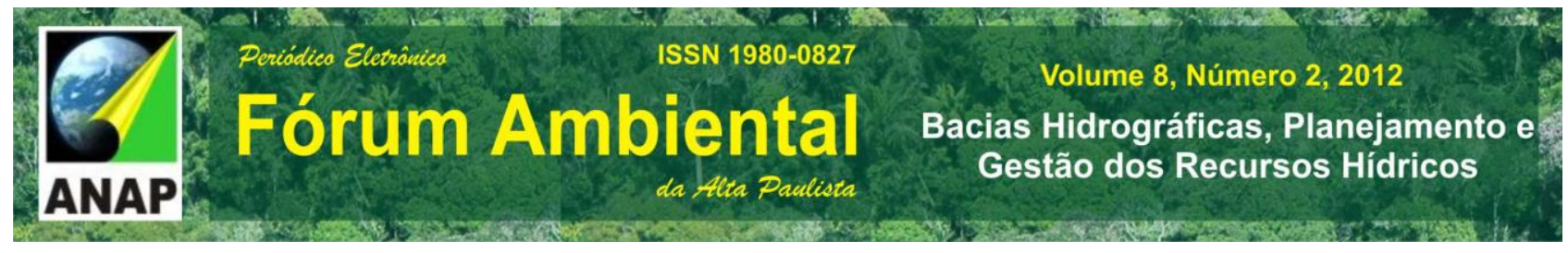

Com o uso do SPRING, foi possível fazer análise dos mapas temáticos de épocas diferenciadas, podendo assim fazer uma análise integrada de como a área vem sendo utilizada. E assim preparar melhor um planejamento ambiental para a área

É preciso entender que as geotecnologias são ferramentas utilizadas para a produção estratégica de mapeamentos temáticos em geral. Aliando isso a um BDG, é um primeiro passo para a criação de um planejamento ambiental do local. Mostrando assim a importância que o SPRING tem nas análises ambientais e multitemporais, podendo ser utilizada em diversas áreas e em diversos locais, e que deve ser recomendadas para todos os pesquisadores em geral.

\section{Bibliografia}

AZEVEDO, E. A.; MANGABEIRA, J. A. C. Mapeamento de uso das terras utilizando processamento digital de imagem de sensoriamento remoto. Campinas, 2001.

BANDEIRA,E.G.; ALVES,C.M.D.; MELO, L.F.S. ANÁLISE TEMPORAL POR IMAGENS LANDSAT DA EXPANSÃO DA FRONTEIRA AGRÍCOLA NO MUNICÍPIO BOM JESUSPI. In:III Simpósio Brasileiro de Ciências Geodésicas e Tecnologias da Geoinformação,2010. Recife. Anais ... Recife,2010. p.001-006.

BARROS GÓES,M.H. , XAVER-DA-SILVA, J. Uma contribuição metodológica para diagnósticos ambientais por geoprocessamento. Parque Estadual de Ibitipoca, Seminário de Pesquisa, 1996, Ibitipoca. Resumos... Ibitipoca: IBAMA, 1996, pp.13-23

CÂMARA, G. Modelos, Linguagens e Arquiteturas para Banco de dados Geográficos. Tese de Doutorado em Computação Gráfica Aplicada. São José dos Campos, INPE, Dezembro de 1995.

FITZ,P.R. Geoprocessamento sem complicação. São Paulo: Oficina de Textos,2008.

FLORENZANO, T. G. Imagens de Satélite para Estudos Ambientais. São Paulo: Oficina de textos, 2002. 


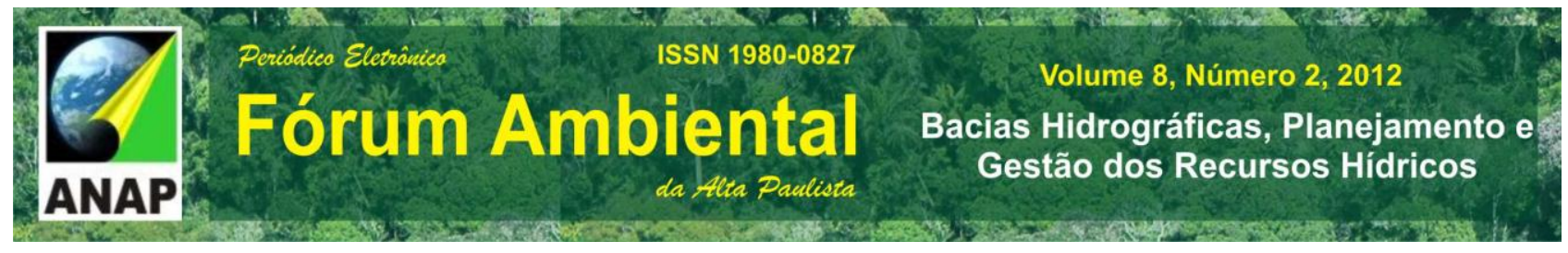

Textos, 2007.

,T. G. Iniciação em Sensoriamento Remoto. São Paulo: Oficina de

GARCIA, G.J. Sensoriamento remoto: princípios e interpretação de imagens. Editora Nobel: São Paulo, 1982

IBGE. Manual Técnico do Uso da Terra. Ed.2, n.7. Rio de Janeiro, 2006.

INSTITUTO NACIONAL DE PESQUISAS ESPACIAIS - INPE Fundamentos de Geoprocessamento - Tutorial. DPI - INPE, 2002 (mimeo).

JENSEN, J. Introductory digital image processing: a remote sensing perspective. New Jersey: Prentice Hall, 1996.

MIRANDOLA , Patricia. Helena. Análise Geo - Ambiental Multitemporal para fins de Planejamento Ambiental: Um exemplo aplicado à Bacia Hidrográfica do Rio Cabaçal Mato Grosso - Brasil. Tese de Doutorado em Geografia do Programa de Pós Graduação em Geografia da Universidade Federal do Rio de Janeiro, 2006,317 paginas.

PROJETO RADAMBRAIL Levantamentos de Recursos Naturais. Ministério das Minas e Energia, Secretaria Geral. Volumes 26 e 27. Rio de Janeiro, 1982.

MOREIRA, M. A. Fundamentos do Sensoriamento Remoto e Metodologias de Aplicação. Viçosa, Ed. UFV, 3ª Ed., 2005. 320p

PARANHOS FILHO, A.C. Sensoriamento remoto ambiental aplicado: Introdução as geotecnologias. Campo Grande: Ed. UFMS, 2008

SAUSEN,T.M. Sensoriamento Remoto e suas Aplicações para Recursos

Natuaris.Coordenadoria de Ensino, Documentação e Programa Especiais. São José dos Campos: INPE, 2002.

XAVIER-DA-SILA, J. ZAIDAN, R. T. Geoprocessamento e análise ambiental: aplicações. $6^{\underline{a}}$ ed. Rio de Janeiro: Bertrand Brasil, 2012 